\title{
Formation of Cubic Boron-Nitride by the Reactive Sputter Deposition of Boron
}

\author{
Alan F. Jankowski \\ Jeffrey P. Hayes \\ Daniel M. Makowiecki \\ Mark A. McKernan
}

This paper was prepared for submittal to the

International Conference on Metallurgical Coatings and Thin Films

April 21-25, 1997

San Diego, CA

March 1997






\section{DISCLAIMER}

This document was prepared as an account of work sponsored by an agency of the United States Government. Neither the United States Government nor the University of California nor any of their employees, makes any warranty, express or implied, or assumes any legal liability or responsibility for the accuracy, completeness, or usefulness of any information, apparatus, product, or process disclosed, or represents that its use would not infringe privately owned rights. Reference herein to any specific commercial product, process, or service by trade name, trademark, manufacturer, or otherwise, does not necessarily constitute or imply its endorsement, recommendation, or favoring by the United States Government or the University of California. The views and opinions of authors expressed herein do not necessarily state or reflect those of the United States Government or the University of California, and shall not be used for advertising or product endorsement purposes. 
Formation of cubic boron-nitride by the reactive sputter deposition of boron

Alan F. Jankowski, Jeffrey P. Hayes, Daniel M. Makowiecki and Mark A. McKeman

University of California, Lawrence Livermore National Laboratory, Livermore CA 94550

\section{ABSTRACT}

Boron-nitride films are synthesized by if magnetron sputtering boron targets where the deposition parameters of gas pressure, flow and composition are varied along with substrate temperature and applied bias. The films are analized using Auger electron spectroscopy, transmission electron microscopy, nanoindentation, Raman spectroscopy and $\mathrm{x}$-ray absorption spectroscopy. These techniques provide characterization of film composition, crystalline structure, hardness and chemical bonding, respectively. Reactive, rf-sputtering process parameters are established which lead to the growth of crystalline BN phases. The deposition of stable and adherent boron nitride coatings consisting of the cubic phase requires $400^{\circ} \mathrm{C}$ substrate heating and the application of a $300 \mathrm{~V}$ negative bias. 


\section{INTRODUCTION}

Boron nitride (BN) coatings are of interest for electronics, optical filters, wear resistance and high hardness. Thin film processing techniques such as laser ablation and ion beam sputtering have been used to deposit BN films. A long-standing industrial objective has been to deposit stable films of cubic boron nitride ( $\mathrm{cBN}$ ), for instance, as a cutting tool coating in applications where diamond or diamond-like materials are not compatible. Stabilization of the $\mathrm{cBN}$ phase in thin films has been achieved through the use of ion-assisted deposition techniques, e.g. high voltage, bias sputtering or ion beam bombardment at the substrate. ${ }^{[1-4]}$ The BN films deposited by these very energetic techniques typically have large intrinsic stresses and poor adhesion. Mechanisms proposed for stabilization of the cubic phase in BN films include both preferential sputtering effects $[5]$, the presence of large stresses $[6,7]$ and subplantation $[8,9]$ wherein low energy ions are implanted below the surface to increase local density. Recently, ion implantation of hexagonal boron nitride $(\mathrm{hBN})$ with $\mathrm{N}_{2}{ }^{+}$was shown to induce a significant proportion of $s p^{3}$ bonding characteristic of $\mathrm{cBN}$ as identified through the near-edge $\mathrm{x}$-ray absorption fine structure. ${ }^{[10]}$ Further examination with core level photoabsorption to study BN defects and metastable bonding configurations confirms that the presence of point defects support models that involve defect creation in the mechanism of $\mathrm{cBN}$ formation. The $s p^{3}$ phase of $\mathrm{BN}$ attained with ion-assisted techniques has an optimal temperature for $\mathrm{CBN}$ growth since over the optimal value the concentration of point defects would decrease by annealing.[11] Similarly, ion-irradiation has been shown to induce $s p^{3}$ bonding whereas un-irradiated regions of a BN film only exhibited $s p^{2}$ bonding as identified with electron energy loss spectroscopy.[7] A less energetic, physical vapor deposition process as well as the use of a multilayered structure could have practical advantages in forming BN films composed of the cubic phase.[12,13]

The hBN phase is commonly used as the target material for most of the sputter deposition processes used to produce hard BN coatings. This can be attributed to the many commercial sources of dense, high purity $\mathrm{hBN}$ targets and the lack of available $\mathrm{cBN}$ or pure boron targets of similar quality. The ablation or sputtering of a material can result in the transport of molecular 
clusters which could potentially promote growth of the target phase.[14] The fabrication of dense, pure boron targets has made it possible to initiate BN deposition without the use of hexagonal phase targets. $[13,15,16]$ Deposition of mass separated ${ }^{11} \mathrm{~B}^{+}$and ${ }^{14} \mathrm{~N}^{+}$ions has been shown to facilitate the formation of $\mathrm{cBN}$ with lower ion energy (500 eV) and substrate temperature $\left(350^{\circ} \mathrm{C}\right) .[17]$ We examine the effects of gas pressure, flow and composition along with substrate temperature and applied bias on the formation of crystalline phases in BN films deposited by rf sputtering pure boron targets using unbalanced planar magnetrons.

\section{EXPERIMENTAL METHOD}

We briefly describe the patented process used to create the sputter targets.[18] Boron powder ( 99.9 at.\% purity) was vacuum sealed in a tantalum container by electron beam welding. The container and its contents were hot isostatically compacted at $1700^{\circ} \mathrm{C}$ in $\mathrm{Ar}$ gas with 0.21 GPa applied pressure for $2-4 \mathrm{hr}$. The container is removed yielding a boron monolithe that has a $2.34 \mathrm{gm} \mathrm{cm}^{-3}$ immersion density and $<0.15 \%$ porosity. The monolithe was machined into right circular cylinders which are individually brazed to a compatible backing plate. X-ray diffraction analysis reveals the targets to be the rhombohedral crystalline phase of boron.

Two vacuum chambers are used for the reactive sputter deposition of BN films. The first chamber is used to establish the baseline effects of sputter gas composition and substrate temperature on the composition and phase formation of BN films. The deposition chamber is cryogenically pumped to a $5.3 \times 10^{-6} \mathrm{~Pa}$ pressure in $12 \mathrm{hrs}$ including a $4 \mathrm{hr}, 100^{\circ} \mathrm{C}$ bake. Reports have indicated that an epitaxial $\mathrm{cBN}$ growth can be enhanced through the use of $\mathrm{Ni}$ epilayers. [19,20] As such, 20-50nm of $\mathrm{Ni}$ is initially sputter deposited using a $0.7 \mathrm{~Pa}$ argon gas pressure onto several of the $\mathrm{Si}$ wafers at room temperature. $C u K \alpha$ x-ray diffraction in the $\Theta / 2 \Theta$ mode reveals a Ni(111) texured deposit. Uncoated sapphire wafers are also used for substrates. The substrate holder is horizontally positioned $9 \mathrm{~cm}$ away from the center of the $6.4 \mathrm{~cm}$ diameter boron target. The substrate temperature is controlled using a Boralectric ${ }^{\mathrm{TM}}$ heater. The Si wafers are heated up to $600^{\circ} \mathrm{C}$, as above this temperature $\mathrm{CuK \alpha} \mathrm{x}$-ray diffraction reveals the formation 
of an orthorhombic phase of nickel silicide. The sputter gas pressure is nominally selected as 1 $\mathrm{Pa}\left(7 \mathrm{mT}\right.$ orr) with a constant $28 \mathrm{cc} \mathrm{min}^{-1}$ flow rate. A partial flow of $\mathrm{N}_{2}$ is incorporated into the Ar flow to yield a 0 to $55 \%$ range of gas composition. The deposition rate is monitored with a calibrated $6 \mathrm{MHz}$ Au coated quartz crystal. An increase in applied forward power from 100 to $300 \mathrm{~W}$ produces a linear increase in deposition rate from to 0.007 to $0.021 \mathrm{~nm} \mathrm{~s}^{-1}$.

A second chamber accomodates the deposition of a hard coating to the surface of cutting tools. The substrate is instrumented for application of a negative bias voltage during film growth. A $20-50 \mathrm{~nm}$ thick layer of either $\mathrm{Ti}$ or $\mathrm{Cr}$ is sputter deposited at room temperature using a 1.1 $\mathrm{Pa}$ Ar gas pressure to promote adhesion of the BN coating on the $25 \mathrm{~mm}$ diameter Si wafers. The substrate is vertically positioned $5 \mathrm{~cm}$ below an array of three $3.3 \mathrm{~cm}$ diameter, magnetrons. At a 1.1 Pa sputter gas pressure, a $\mathrm{BN}$ deposition rate of $0.02 \mathrm{~nm} \mathrm{~s}^{-1}$ was produced using an 80 Watt forward target power. A negative bias voltage is applied to the substrate by drawing-off $5 \%$ of the rf power applied to the target. A portion of the ionized sputter gas will then strike the substrate and modify the coating structure. A typical cosine distribution for boron with a sputter yield of 0.2 is assumed using Ar gas at a $300 \mathrm{~V}$ target potential. The ion current density at the substrate surface is then approximated to range from 16 to $2 \mathrm{~mA} \mathrm{~cm}-2$ as the negative bias voltage ranges from 50 to 400 Volts yielding an ion:neutral flux that varies from 21 to 3 , respectively. The sputter gas pressure is increased to $3 \mathrm{~Pa}$ to assess further effects of film stress.

The BN thin films are characterized for composition, morphology, crystalline structure, mechanical hardness and chemical bonding. The film composition is measured using Auger electron spectroscopy (AES) coupled with depth profiling by Ar sputtering. The intensities of the $\mathrm{B}, \mathrm{C}, \mathrm{N}$, and $\mathrm{O} K L L$ Auger electrons as data accumulated in the derivative mode are used to compute the atomic concentrations. Transmission electron microscopy (TEM) is used to assess film morphology and crystallinity. Bright field imaging in plan view reveals the film grain structure. Dark field imaging coupled with electron diffraction reveals the crystallinity of the films. Selected area diffraction patterns are used to measure interplanar spacings as calibrated to a Au standard. The accompanying geometric relationships between diffracting planes leads to 
appropriate crystalline phase identification. Conventional light microscopy may then be used to compare the effects of intrinsic stress on macroscopic film adhesion.

The hardness of the submicron thick films are measured with a nanoindenter. [21] A Berkovich (three-sided pyramid) indenter is used to produce arrays of indentations at each of several depths. Loads are measureable above $0.25 \mu \mathrm{N}$ and indentation depths to within $0.3 \mathrm{~nm}$. A variation in hardness will occur with different indentation depths. [22] The substrate will influence the measured film hardness at some critical depth. In practice, the film hardness should be determined at the most shallow indentation depths. The ASTM recommendation to determine coating hardness at depths $d$ less than $10 \%$ of the film thickness $t$ is followed whenever possible. [23] The analysis of nanoindentation load-displacement curves was developed for bulk homogeneous materials.[21,24,25] Analysis procedures have evolved to better define parameters such as true contact area which are used in the detemination of hardness for stiff materials as well as inhomogeneous systems.[26,27] Although there are limitations imposed by analizing inhomogeneous and hard materials as BN, the coating-substrate hardness is determined using the method proposed by Oliver and Pharr. ${ }^{[28,29]}$ The hardness values provide for comparisons that can be correlated to morphology, crystallinity and chemical bonding.

Raman spectroscopy characterizes the vibrational states of chemical bonds within the BN films. There are many crystalline BN phases including rhombohedral and wurtzite. The distinct structures and chemical bonding features are of the hexagonal and cubic phases. The Raman phonon of hBN appears at $1367 \mathrm{~cm}^{-1}$ as representative of $s p^{2}$ hybridized, planar bonding. The transverse optical (TO) and longitudinal optical (LO) modes of cBN appear at 1057 and 1306 $\mathrm{cm}^{-1}$, respectively, as representative of $s p^{3}$ tetrahedral bonding. The relative intensity of the TO and LO modes for $\mathrm{CBN}$ can vary as BN is noted to have strong Raman anisotropy. [28]

Near-edge $\mathrm{x}$-ray absorption fine structure (NEXAFS) associates unique spectral features in the boron and nitrogen $1 s$ photoabsorption cross sections with resonances that are specific to discrete BN phases. [29] The photon energy of monochromatic synchrotron radiation is scanned through the core-level edge while monitoring the electron yield to measure the core-level photoabsorption cross section. The low-energy, long mean-free-path electron emission 
dominates the signal yielding a bulk sensitive measurement of the film. The transition of $1 s$ initial states into p-like empty final states is associated with $s p^{2}$ hybridized, planar bonding that is characteristic of $\mathrm{hBN}$ and appears as the narrow, intense transition at $192 \mathrm{eV}$. This $\pi^{*}$ resonance is absent in $s p^{3}$ tetrahedrally bonded materials as $c B N$ which uniquely evidence an absorption maximum step into $\sigma^{*}$ continuum states above $194 \mathrm{eV}$. The presence of nitrogen void defects is indicated by three satellite peaks above the $192 \mathrm{eV}$ peak in the B $1 s$ spectra.[10] Whereas the $192 \mathrm{eV}$ peak is indicative of $\mathrm{B}-\left(\mathrm{N}_{3}\right)$ bonding, the additional peaks correspond in progression to $\mathrm{B}-\left(\mathrm{BN}_{2}\right), \mathrm{B}-\left(\mathrm{B}_{2} \mathrm{~N}\right)$ and finally elemental boron bonding. The diffuse peak for elemental boron at $194 \mathrm{eV}$ can be correlated with some degree of planarization of $s p^{3}$ tetrahedral bonding, similar in signature to the sub-surface boron layer that forms in silicon. [30]

\section{EXPERIMENTAL RESULTS \& ANALYSIS}

The sputter gas composition and substrate temperature are initially varied to determine the effects on film composition and structure. AES depth profiles indicate that the BN coatings have a constant composition through the film.[13] An average film composition of $47 \pm 2$ at.\% B is found over the 25 to $55 \% \mathrm{~N}_{2}$ gas composition range for $>200{ }^{\circ} \mathrm{C}$ substrate heating. Carbon and oxygen are not found in the $\mathrm{BN}$ films although the detection limit for these impurities is approximately $2-3$ at.\%. Raman spectra of the $0.15-0.20 \mu \mathrm{m}$ thick BN films deposited at $1 \mathrm{~Pa}(7$ mTorr) are offset in intensity to accentuate the spectral features of individual curves (Fig. la-e) over the 50 to $600{ }^{\circ} \mathrm{C}$ temperature range. The intensity of the $\mathrm{hBN}$ peak increases as the substrate temperature increases to $350^{\circ} \mathrm{C}$. An increase in temperature above $350^{\circ} \mathrm{C}$ produces an asymmetry in the $\mathrm{hBN}$ peak towards the wavenumber corresponding to the $\mathrm{LO}$ mode of $\mathrm{cBN}$. These Raman spectra infer that an $s p^{2}$ bonded structure with some disorder is formed at room temperature. A refined $\mathrm{hBN}$ crystal growth results with an increase above room temperature. Further increase in substrate temperature then disorders the well defined $s p^{2}$ bonding of $h B N$ to possibly include some small fraction of $s p^{3}$ bonding. 
Substrate bias is then applied during deposition to stabilize $s p^{3}$ bonding in the BN films. To promote cBN formation, the substrate is heated from 400 to $500{ }^{\circ} \mathrm{C}$ and the sputter gas pressure is varied using an $\mathrm{Ar}-25 \% \mathrm{~N}_{2}$ gas mixture at a nominal flow of 25 to $30 \mathrm{cc} \mathrm{min}^{-1}$. The effects of applied bias in the Raman spectra of $0.15-0.30 \mu \mathrm{m}$ thick films deposited at $400{ }^{\circ} \mathrm{C}$ using a 1.1 $\mathrm{Pa}$ ( $8 \mathrm{mTorr}$ ) sputter gas pressure are shown noting that individual curves (Fig. 1f-i) are offset in intensity to accentuate bonding features. A BN structure with $s p^{2}$ bonding is formed with a $-70 \mathrm{~V}$ bias. A diffuse peak at $1100 \mathrm{~cm}^{-1}$, characteristic of the TO mode seen for the $s p^{3}$ bonding of $\mathrm{cBN}$ appears with a $-150 \mathrm{~V}$ bias. The characteristic $s p^{2}$ bonding at $1367 \mathrm{~cm}^{-1}$ vanishes while the broad peak at $1100 \mathrm{~cm}^{-1}$ increases in intensity with further bias increase to $300 \mathrm{~V}$. The intensity of the broad peak at $1100 \mathrm{~cm}^{-1}$ is reduced with additional bias increase to $400 \mathrm{~V}$. The application of negative bias at $400{ }^{\circ} \mathrm{C}$ destabilizes $s p^{2}$ bonding as found in $\mathrm{hBN}$ and promotes $s p^{3}$ bonding as found in $\mathrm{cBN}$. The deposition-related trends in chemical bonding as interpreted from these Raman spectra are qualitative at this point of the analysis. Quantification of the cBN content can be uncertain as Raman peak shapes are found to be dependent on the film grain size.[31] The bias-assisted deposits are next characterized with TEM and NEXAFS to confirm changes in crystallinity and chemical bonding, and to quantify the cubic phase content.

The BN films deposited without an adhesion layer are removed from the Si substrates and examined in plan view using TEM. The bright field (BF) image (Fig. 2a) of a BN film deposited with a $-70 \mathrm{~V}$ bias at $1.1 \mathrm{~Pa} \mathrm{Ar}-40 \% \mathrm{~N}_{2}$ gas pressure reveals a fine-grained, continuous microstructure. The rings (Fig.2b) of the electron diffraction pattern (EDP) indicate a polycrystalline structure. The d-spacings are $0.350 \pm 0.005,0.2101 \pm 0.0008$, and $0.1205 \pm 0.0002$ nm. The dark fild (DF) image (Fig. 2c) generated from the broad, intense inner ring of the EDP shows a continuous, fine grained diffracting volume. The BN structure appears to be single phase and nanocrystalline as the DF illumination of the diffracting 2-5nm sized grains can be easily translated with small sample tilting. The d-spacings of this BN film best fit the turbostratic boron nitride (tBN) phase with previously reported d-spacings of 0.356 and 0.212 $n m$. ${ }^{[7,32]}$ Note that the $d_{c B N}(111)$ of $0.2088 \mathrm{~nm}$ or the $d_{\mathrm{hBN}}(10.0 / 10.1)$ of $0.217 / 0.206 \mathrm{~nm}$ and the $d_{h B N}(11.0 / 11.2)$ of $0.125 / 0.117 \mathrm{~nm}$ are not probable reflections. ${ }^{[33,34]}$ The tBN phase 
identification is consistent with the bonding trends found in the Raman spectra (e.g. Fig. 1f). The BN film deposited at low bias has disordered $s p^{2}$ bonding.

Raman spectra (Fig. 1h) indicate the probable presence of $s p^{3}$ bonding in the $-300 \mathrm{~V}$ bias deposit. The plan view BF image (Fig. 2d) of a BN film deposited on a $500^{\circ} \mathrm{C}$ substrate with a $300 \mathrm{~V}$ bias at $1.1 \mathrm{~Pa} \mathrm{Ar}-25 \% \mathrm{~N}_{2}$ gas pressure appears to have large-scale fracturing with a continuous subgrain microstructure a mosaic appearance likely attributable to film curvature. The rings of the EDP (Fig. 2e) indicate a polycrystalline structure. The DF image (Fig. 2f) generated from the narrow, most intense inner ring of the EDP shows a uniformly dispersed, fine grained diffracting volume. DF illumination of many of the diffracting 2-5nm sized nanocrystals can be easily translated with small sample tilting. From the innermost ring outward, the computed interplanar spacings are $0.2096 \pm 0.0005,0.1283 \pm 0.0002,0.1093 \pm 0.0001$, $0.0907 \pm 0.0001,0.0830 \pm 0.0001$, and $0.0741 \pm 0.0001 \mathrm{~nm}$. These $\mathrm{d}$-spacings can be indexed to the (111), (220), (311), (400), (331) and (422) of a cubic phase with a $0.3625 \pm 0.0003 \mathrm{~nm}$ lattice parameter, closely matching the $\mathrm{cBN}$ powder diffraction file value of $0.3616 \mathrm{~nm}$. Optical microscopy confirms that the $\mathrm{BN}$ film deposited at $500^{\circ} \mathrm{C}$ with a $-300 \mathrm{~V}$ bias using a $1.1 \mathrm{~Pa}(8$ mTorr) pressure has a crazed surface whereas a $400^{\circ} \mathrm{C},-300 \mathrm{~V}$ bias deposit using $2.1 \mathrm{~Pa}(15$ mTorr) gas pressure appears specular, stress-free and entirely adherent to the substrate. The sputter gas pressure may effect phase formation in addition to film stress. Quantification of cBN content requires the following NEXAFS characterization.

The NEXAFS spectrum (Fig. 3) show the effects of sputter gas pressure and temperature on the stabilization of the $\mathrm{cBN}$ phase in films deposited with a $-300 \mathrm{~V}$ substrate bias. The presence of the $\mathrm{cBN}$ phase is evident in the TEM results (Fig. 2e,f) for the BN film deposited at $500^{\circ} \mathrm{C}$ using a $1.1 \mathrm{~Pa}(8 \mathrm{mTorr})$ gas pressure and a $-300 \mathrm{~V}$ bias. This BN film generated a Raman spectrum similar to the curve for the $1.1 \mathrm{~Pa}, 400^{\circ} \mathrm{C},-400 \mathrm{~V}$ bias deposit (Fig. 1i) which suggests the presence of a fine grained deposit with some $\mathrm{cBN}$ content. The NEXAFS spectrum resolves the contribution of both $s p^{2}$ and $s p^{3}$ bonding for the $1.1 \mathrm{~Pa}, 500^{\circ} \mathrm{C},-300 \mathrm{~V}$ bias sample. The $s p^{2}$ bonding features are evident at the $\pi^{*}$ edge indicative of hBN and the defect structure associated with sputter deposited films. The abrupt transition characteristic of $s p^{3}$ bonding found 
in $\mathrm{cBN}$ is present at the $\sigma^{*}$ edge with additional $s p^{2}$ features at higher energy. A Gaussian fit of the spectra beyond the $\sigma^{*}$ edge to determine the relative $s p^{2}$ and $s p^{3}$ intensities above baseline permits quantification of the phase content. $[10,11]$ The NEXAFS spectra indicates the $1.1 \mathrm{~Pa}$ (8 mTorr), $500{ }^{\circ} \mathrm{C},-300 \mathrm{~V}$ bias sample has a $30 \% s p^{3}$ (cBN phase) content whereas the $2.1 \mathrm{~Pa} \mathrm{(15}$ mTorr), $400{ }^{\circ} \mathrm{C},-300 \mathrm{~V}$ bias deposit has a $0 \% s p^{3}$ (cBN phase) content. The $1.1 \mathrm{~Pa}(8 \mathrm{mTorr}$ ), $400{ }^{\circ} \mathrm{C},-300 \mathrm{~V}$ bias deposit evidences a $80 \% s p^{3}$ (cBN phase) content which is consistent with the (TO mode) broad peak indicative of cBN in the Raman spectra (Fig. 1h). Bias voltage, substrate temperature and sputter gas pressure (coupled with source-to-substrate separation) each effect stabilization of $s p^{3}$ bonding in the BN films.

The quantification of $s p^{3}$ bonding in the BN films using the NEXAFS spectrum is consistent with the nanoindentation measurements of these same BN films. The convergence of all indentation curves to the Si substrate hardness is evident for $d / t>1$. The smallest indentation depths are resolvable for the hardest films. The hardness of each film (Fig. 4) is found at the shallow indentation depths corresponding to the small $d / t(\sim 0.1)$ values. The BN film with $80 \%$ $s p^{3}$ bonding has a hardness of $41 \pm 6 \mathrm{GPa}$ whereas the BN films with $30 \%$ and $0 \% s p^{3}$ bonding have hardness values of $10 \pm 2$ and $1.0 \pm 0.4 \mathrm{GPa}$, respectively. A pure Boron film sputter deposited using $1 \mathrm{~Pa}(7 \mathrm{mTorr}) \mathrm{Ar}$ gas pressure without substrate bias at $200^{\circ} \mathrm{C}$ has a hardness of $27 \pm 2 \mathrm{GPa}$. The B and BN film hardnesses correspond well with values commonly reported for bulk crystals of pure Boron and (by percent $s p^{3}$ bonding content) $\mathrm{cBN}$. Scatter in the hardness measurements of the $\mathrm{BN}$ films with $s p^{3}$ bonding is a probable consequence of the stress state associated with these films, noting that the $s p^{3}$ bonded BN films have a tendency to release from the substrates during indentation testing.

The Raman and NEXAFS spectra are representative of the BN films and not the substrate or metal epilayers. Raman and NEXAFS characterization of the epilayer-substrate combinations did not produce any of the spectral features reported for the BN films. Any enhancement of cBN growth using a metal epilayer may require higher substrate temperatures and/or the use of single crystals. For example, results reported for $\mathrm{cBN}$ growth on $\mathrm{Ni}$ using hot-filament assisted, if plasma chemical vapor deposition required substrate temperatures of $900-1100^{\circ} \mathrm{C} .[19,20]$ 


\section{DISCUSSION}

The deposition of a $\mathrm{cBN}$ film from a $\mathrm{hBN}$ target requires an energetic ion-assisted process. ${ }^{[1-4]}$ For example, only the $\mathrm{tBN}$ and $\mathrm{hBN}$ phases are found in films for pulsed laser ablation of $\mathrm{hBN}$ onto substrates at elevated temperature without the energetic component of a coincident ion irradiation.[35] Stabilization of the cBN phase by increasing substrate bias when sputtering a boron target using Ar- $\mathrm{N}_{2}$ gas mixture is a clear indication that an energetic process is needed in comparison to growth of the $\mathrm{hBN}$ phase.

Similar to our approach for depositing $\mathrm{cBN}$, Ulrich, et al. achieved success through rf sputtering hBN targets with an unbalanced magnetron at $0.1 \mathrm{~nm} / \mathrm{s}$ using an applied substrate bias from an if generator.[36] The formation of $\mathrm{cBN}$ occurs when the substrate is at moderate temperature $\left(527^{\circ} \mathrm{C}\right)$ and above a threshold potential $(>75 \mathrm{eV})$. However, the deposition process is very energetic using such a low $(0.6 \mathrm{mTorr})$ sputter gas pressures at a short $(3.5 \mathrm{~cm})$ source-tosubstrate separation. The maximum $\mathrm{cBN}$ content correlates with maximum compressive stress (25 GPa in a $0.2 \mu \mathrm{m}$ thick film) produced over a narrow range of substrate potentials $(85 \pm 5 \mathrm{eV})$. At higher potentials the $\mathrm{cBN}$ content steadily decreases. The existence of an energy threshold in applied negative bias was also found by Tsuda, et al. for $\mathrm{cBN}$ formation from an $\mathrm{hBN} \operatorname{target}$ [37] A threshold substrate bias greater in magnitude than $-250 \mathrm{~V}$ was required to induce $\mathrm{cBN}$ formation at a higher deposition rate $(1 \mathrm{~nm} / \mathrm{s})$, higher Ar sputter gas pressure (16 mTorr), and higher substrate temperature $\left(600^{\circ} \mathrm{C}\right)$. The higher bias and temperature thresholds correspond with less energetic sputtered neutrals that result from scattering in higher gas pressure. The maximum cBN content was also found over a narrow range of substrate potentials $(300 \pm 50$ $\mathrm{eV}$ ), beyond which the $\mathrm{cBN}$ content would decline.

Earlier observations of a low kinetic energy threshold for $\mathrm{cBN}$ stabilization was made by Kidner, et al. when magnetron sputtering an hBN target in a nitrogen plasma produced by an electron cyclotron resonance source onto heated substrates with an applied negative bias.[38] The $20 \mathrm{~cm}$ source-to-substrate separation used should provide for complete thermalization of 
sputtered neutrals in the presence of a $1 \mathrm{mTorr}$ working gas pressure. Therefore, mobility of the sputtered neutrals at the substrate are dependent upon heating (to $850^{\circ} \mathrm{C}$ ) and applied bias. Beyond a $-105 \mathrm{~V}$ threshold, $\mathrm{cBN}$ was formed and likewise as the bias potential increased, the reflection high energy electron diffraction patterns for $\mathrm{cBN}$ became more diffuse.

The use of a pure Boron target was reported by Jensen, et al. to sputter deposit BN films [39] The use of substrate bias and/or temperature to influence phase formation was not presented and therefore, only hBN films were formed which is already within the capability of low temperature processing from $\mathrm{BN}$ targets. Most recently, the deposition of $s p^{3}$ bonded cubic $\mathrm{BN}: \mathrm{C}$ is shown possible by Johansson, et al. at low substrate temperatures $\left(150^{\circ} \mathrm{C}\right)$ and low energy $(110 \mathrm{eV})$ ion bombardment with a high ion:neutral flux through the use of a $\mathrm{B}_{4} \mathrm{C}$ target.[40] A $10 \mathrm{~cm}$ source-to-substrate separation is used coupled with a 3 mTorr working gas pressure (that includes a $<1.5 \mathrm{mT}$ Torr $\mathrm{N}_{2}$ partial pressure) to yield $0.05-0.1 \mathrm{~nm} \mathrm{~s}^{-1}$ growth rates similar to the present study. At or above $250 \mathrm{~V}$ bias, only hBN is found. Again an upper energy threshold is indicated noting that the increase in substrate potential coincided with the decease in ions:neutral flux. Johansson, et al. suggest that ion bombardment with low energies and higher fluxes provides a deposition parameter window for $\mathrm{cBN}$ growth (in agreement with results for if sputtering hBN targets [9]) which is not accounted for by momentum transfer modelling ${ }^{[41,42]}$ but is suggested by the subplantation model [8]. However, the present pure boron target findings do not show stabilization of the cBN phase in films using low bias potentials for similar ion:neutral flux ratios $[40]$ used for the $\mathrm{B}_{4} \mathrm{C}$ target sputtering.

The examples of prior studies as well as present findings indicate that there is no one specific deposition method to produce $\mathrm{cBN}$ films. [43] However, it is clear that the formation of cBN requires an energetic threshold and is optimized over a well-defined range of energetic bombardment. Cubic BN films deposited from hBN targets are almost invariantly stressed compressively, and have resulted in substrate fracture when adherent. The suggestion has been put forth for stabilizing $\mathrm{cBN}$ in adherent films through the use of high ion energies and high substrate temperatures. [44] This suggestion appears contrary to the many findings which show a decrease in $\mathrm{cBN}$ content for elevated substrate temperatures. The control of stress will continue 
to be a challenge in $\mathrm{cBN}$ coatings for high hardness and wear resistance. The use of Boron targets may expand the range of deposition parameters accessible for $\mathrm{cBN}$ formation in adherent films. Our early results do show $30-80 \% \mathrm{cBN}$ content in adherent, although crazed coatings. The current results document one of the lowest substrate temperatures and negative bias potentials used for $\mathrm{cBN}$ deposition. The use of sputter gas pressure as a deposition parameter to stabilize the growth of adherent $\mathrm{cBN}$ coatings when sputtering from a dense boron target may prove promising for cutting tool applications.

\section{SUMMARY}

Thin-film fabrication of BN samples has been accomplished by reactive sputter deposition from a dense, pure boron target. The near stoichiometric (47 at.\% B) film composition is found to be insensitive to gas composition $\left(25-55 \% \mathrm{~N}_{2}\right)$ and substrate temperature $\left(200-600^{\circ} \mathrm{C}\right)$ over the limited range of deposition rates $\left(<0.04 \mathrm{~nm} \mathrm{~s}^{-1}\right)$ examined. The control of substrate temperature and bias allow for the stabilization of BN films with $s p^{2}$ and $s p^{3}$ bonding. Although not all combination have been explored, the following trends are confirmed for BN films deposited using a 1.1 $\mathrm{Pa}$ Ar- $\mathrm{N}_{2}$ sputter gas pressure as characterized using Raman spectroscopy, NEXAFS and TEM. Low temperature $\left(<200^{\circ} \mathrm{C}\right)$ and low negative bias $(<150 \mathrm{~V})$ produce films with structures characteristic of amorphous or turbostratic BN. Substrate temperatures from 200 to $350^{\circ} \mathrm{C}$ and the application of low negative bias potentials stabilize the growth of films with structures characteristic of hexagonal BN. The application of negative bias from 300 to $400 \mathrm{~V}$ for $400-500^{\circ} \mathrm{C}$ heated substrates stabilizes the formation of the $\mathrm{cBN}$ phase. A $41 \mathrm{GPa}$ hardness is measured for a BN film consisting of $80 \%$ (cBN) $s p^{3}$ bonding.

\section{ACKNOWLEDGMENTS}

This work was supported by the Mechanical Engineering Manufacturing Technology Thrust and the Basic Energy Sciences Synthesis and Processing Center for Surface Hardness. 
The authors thank M. Wall of LLNL for the transmission electron microscopy, I. Jimenez for the $\mathrm{x}$-ray absorption measurements performed at the Stanford Synchrotron Radiation Laboratory and the Advanced Light Source at Lawrence Berkeley Laboratory, and T.Y. Tsui who performed several of the nanoindentation measurements while visiting Oak Ridge National Laboratory. This work was performed under the auspices of the United States Department of Energy by Lawrence Livermore National Laboratory under contract \#W-7405-Eng-48.

\section{REFERENCES}

1 Kester, D., K. Alley, D. Lichtenwainer and R. Davis, J. Vac. Sci. Technol., A12 (1994) 3074.

2 Friedmann, T., P. Mirkarimi, D. Medlin, K. McCarty, E. Klaus, D. Boehme, H. Johnsen, M. Mills, D. Ottesen and J. Barbour, J. Appl. Phys., 76 (1994) 3088.

3 Wada, T., and N. Yamashita, J. Vac. Sci. Technol., A10 (1992) 515.

4 Tanabe, N., T. Hayashi and M. Iwaki, Diamond Relat. Mater., 1 (1992) 883.

5 Reinke, S., M. Kuhr and W. Kulisch, Diamond Relat. Mater., 3 (1994) 341.

6 McKenzie, D., W. McFall, W. Sainty, C. Davis and R. Collins, Diamond Relat. Mater., 2 (1993) 970.

7 Medlin, D.L., T.A. Friedmann, P.B. Mirkarimi, P. Rez, M.J. Mills and K.F. McCarty, J. Appl. Phys., 76 (1994) 295.

8 Robertson, J., Diamond Relat. Mater., 5 (1996) 519.

9 Ulrich, S., J. Schwan, W. Donner and H. Ehrhardt, Diamond Relat. Mater., 5 (1996) 548.

10 Jimenez, I., A. Jankowski, L. J. Terminello, J. A. Carlisle, D. G. J. Sutherland, G. L. Doll, J.V. Mantese, W. M. Tong, D. K. Shuh and F. J. Himpsel, Appl. Phys. Lett., 68 (1996) 2816.

11 Jimenez, I., A.F. Jankowski, L.J. Terminello, D.G.J. Sutherland, J.A. Carlisle, G.L. Doll, J.V. Mantese, W.M. Tong, D.K. Shuh and F.J. Himpsel (submitted for publication). 
12 Barnett, S., and M. Shinn, Ann. Rev. Mater. Sci., 24 (1994) 481.

13 Jankowski, A., J. Hayes, M. McKernan and D. Makowiecki, LLNL UCRL-JC (1995).

14 Thornton, J., in Deposition Technologies for Films and Coatings, edited by R. Bunshah, Noyes Publication, Park Ridge (1982) p. 187.

Makowiecki, M., A. Jankowski, M. McKernan and R. Foreman, J. Vac. Sci. Technol., A8 (1990) 3910.

16 McKernan, M., D. Makowiecki, P. Ramsey and A. Jankowski, Surf. Coatings Technol., 49 (1991) 411.

17 Hofsass, H., C. Ronning, U. Griesmeier, M. Gross, S. Reinke and M. Kuhr, Appl. Phys. Lett., 67 (1995) 46.

18 Makowiecki, D.M., and M.A. McKernan, Fabrication of Boron Sputter Targets, U.S. Patent No. 5,392,981 (February 28, 1995).

19 Zhang, F., Y. Guo, Z. Song and G. Chen, Appl. Phys. Lett., 65 (1994) 971.

20 Song, Z., F. Zhang, Y. Guo and G. Chen, Appl. Phys. Lett., 65 (1994) 2669.

21 Doemer, M. and W. Nix, J. Mater. Res., 1 (1986) 601.

22 Fabes, B.D., W.C. Oliver, R.A. McKee and F.J. Walker, J. Mater. Res., 7 (1992) 3056.

23 ASTM Standard E 92, Annual Book of Standards 3.01, American Society for Testing and Materials, Philadelphia (1987) p.264.

24 Pharr, G.M., W.C. Oliver and F.R. Brotzen, J. Mater. Res., 7 (1992) 613.

Oliver, W.C. and G.M. Pharr, J. Mater. Res., 7 (1992) 1564.

Loubet, J.L., J.M. Georges and J. Meille, in Microindentation Techniques in Materials Science and Engineering, edited by P.J. Blau and B.R. Lawn, American Society for Testing and Materials, Philadelphia (1986) pp. 72-89.

27 Hainsworth, S.V., H.W. Chandler and T.F. Page, J. Mater. Res., 11 (1996) 1987. 
28 Huong, P., Diamond Relat. Mater., 1 (1991) 33.

29 Terminello, L.J., A. Chaiken, D.A. Lapiano-Smith, G.L. Doll and T. Sato, J. Vac. Sci. Technol., A12 (1994) 2462.

30 McLean, A.B., L.J. Terminello, and F.J. Himpsel, Phys. Rev., B41 (1990) 7694.

31 Namba Y., E. Heidarpour and M. Nakayama, J. Appl. Phys., 72 (1992) 1748.

32 Thomas Jr., J., N. Weston and T. O'Connor, J. Am. Chem Soc., 84 (1963) 4619.

33 JCPDS-ICDD, cBN File No. 25-1033 (1992).

34 JCPDS-ICDD, hBN File No. 34-0421 (1992).

35 Friedmann, T., K. McCarty, E. Klaus, J. Barbour, W. Clift, H. Johnsen, D. Medlin, M. Mills and D. Ottesen, Thin Solid Films, 237 (1994) 48.

36 Ulrich, S., J. Scherer, J. Schwan, I. Barazen, K. Jung, M. Scheib and H. Ehrhardt, Appl. Phys. Lett., 68 (1996) 909.

37 Tsuda, O., Y. Yamada, T. Fujii and T. Yoshida, J. Vac. Sci. Technol. A, 13 (1995) 2843.

38 Kidner, S., C.A. Taylor II and R. Clarke, Appl. Phys. Lett., 64 (1994) 1859.

39 Jensen, H., U.M. Jensen and G. Sorensen, Appl. Phys. Lett., 66 (1995) 1489.

40 Johansson, M.P., I. Ivanov, L. Hultman, E.P. Monger, and A. Schutze, J. Vac. Sci. Technol. A, 14 (1996) 3100.

41 Kester, D.J. and R. Messier, J. Appl. Phys., 72 (1992) 504.

42 Mirkarimi, P.B., K.F. McCarty, D.L. Medlin, T.A. Friedmann, E.J. Klaus, G.F. Cardinale and D.G. Howitt, J. Mater. Res., 9 (1994) 2925.

43 Yoshida, T., Diamond Relat. Mater., 5 (1996) 501.

44 Reinke, S., M. Kuhr and W. Kulisch, Diamond Relat. Mater., 5 (1996) 508. 


\section{FIGURE CAPTIONS}

1 Raman spectra of BN films show changes in chemical bonding with (a-e) substrate temperature $\left({ }^{\circ} \mathrm{C}\right)$ for no bias and (f-i) applied bias $(\mathrm{V})$ for $400^{\circ} \mathrm{C}$ deposits.

2 Transmission electron microscopy, plan view imaging in (a) bright field, (b) diffraction and (c) dark field of a BN film deposited with a $-70 \mathrm{~V}$ bias along with (d) bright field, (e) diffraction and (f) dark field imaging of a BN film deposited at $500^{\circ} \mathrm{C}$ with a $-300 \mathrm{~V}$ bias.

3 Near edge $\mathrm{x}$-ray absorption fine structure of $\mathrm{BN}$ films deposited with a $-300 \mathrm{~V}$ bias have different $s p^{2}$ and $s p^{3}$ contents as dependent on sputter gas pressure and substrate temperature.

4 Nanoindentation variation of Hardness (GPa) with fractional indent depth through the coating

$(d / t)$ for a pure Boron coating and the BN films (of Fig. 3) deposited with a $-300 \mathrm{~V}$ bias . 




Figure 1 




Figure 2 




Figure 3 




Figure 4 


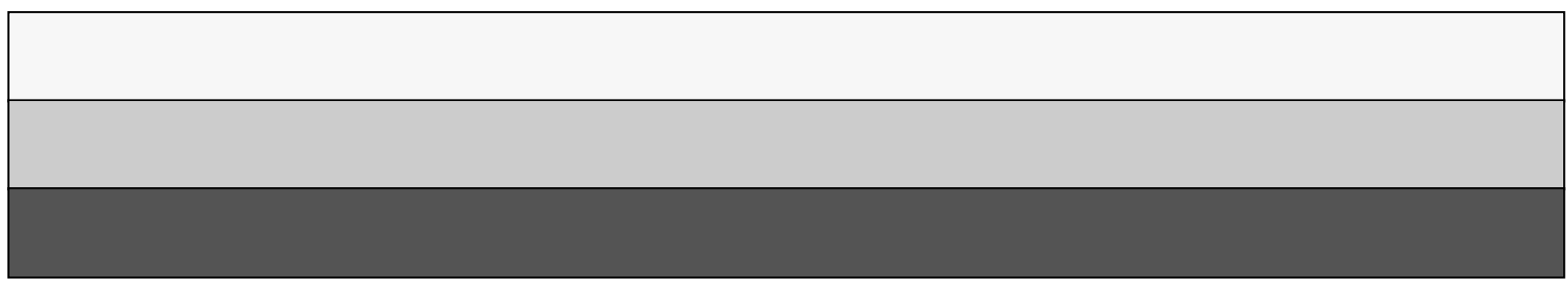

